Discussion Paper No. 02-31

\title{
Recycling of Eco-Taxes, Labor Market Effects and the True Cost of Labor - A CGE Analysis
}

Klaus Conrad and Andreas Löschel

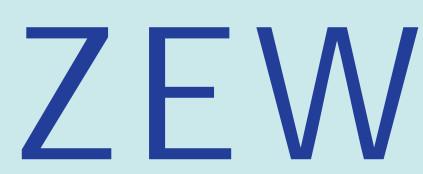

Zentrum für Europäische Wirtschaftsforschung $\mathrm{GmbH}$

Centre for European Economic Research 
Discussion Paper No. 02-31

\section{Recycling of Eco-Taxes, Labor Market Effects and the True Cost of Labor -A CGE Analysis}

Klaus Conrad and Andreas Löschel

Download this ZEW Discussion Paper from our ftp server:

ftp://ftp.zew.de/pub/zew-docs/dp/dp0231.pdf

Die Discussion Papers dienen einer möglichst schnellen Verbreitung von neueren Forschungsarbeiten des ZEW. Die Beiträge liegen in alleiniger Verantwortung der Autoren und stellen nicht notwendigerweise die Meinung des ZEW dar.

Discussion Papers are intended to make results of ZEW research promptly available to other economists in order to encourage discussion and suggestions for revisions. The authors are solely responsible for the contents which do not necessarily represent the opinion of the ZEW. 


\section{Nontechnical Summary}

Computable general equilibrium (CGE) modeling has provided a number of important insights about the interplay between environmental tax policy and the pre-existing tax system. In this paper, we emphasize that a labor market policy of recycling tax revenues from an environmental tax to lower employers' non-wage labor cost depends on how the costs of labor are measured in CGE models. We propose an approach which combines neoclassical substitutability and fixed factor proportions. This cost-price approach uses Leontief partially fixed factor proportions to identify both a disposable or variable part and a bound or fixed portion of each input. The true cost, or cost price, of any input consists of its own price plus the costs associated with the portion of that input bound to other inputs. As an example, the cost of an additional worker includes not just salary, but also the costs of inputs tied to the worker (e.g. office equipment, electricity, material, etc.). Within the cost-price framework, the demand for an input can be separated into a committed component that is linked to the use of other inputs and a disposable component which is free for substitution. At one extreme, when the disposable quantities of all inputs equal zero, no factor substitution is possible and the cost-price approach reduces to the Leontief fixed-proportion case. At the other extreme, when the committed quantities of all inputs are zero, the neoclassical model is relevant and the costprice of any input equates the market price. We econometrically estimate cost-share equations in cost prices and then use cost prices instead of market prices to investigate the double dividend hypothesis. We present both CGE simulation results based on a $\mathrm{CO}_{2}$ tax and the recycling of its revenues to reduce the non-wage labor cost. One simulation is based on the market price of labor and the other on the user cost of labor. We found a double dividend under the first approach but not under the second one. Policy makers have often heard the economist's adage that the outcome of a policy is ambiguous and depends on assumptions made. This fact does not make our consulting work very attractive. However, we think that our point - that user costs of labor matter more than the normal wage costs - is intuitively attractive when arguing about the double dividend hypothesis. 


\title{
Recycling of eco-taxes, labor market effects and the true cost of labor - a CGE analysis*
}

\author{
K. Conrad and A. Löschel
}

Mannheim University and Centre for European Economic Research (ZEW), Mannheim

\begin{abstract}
Computable general equilibrium (CGE) modeling has provided a number of important insights about the interplay between environmental tax policy and the pre-existing tax system. In this paper, we emphasize that a labor market policy of recycling tax revenues from an environmental tax to lower employers' non-wage labor cost depends on how the costs of labor are modeled. We propose an approach which combines neoclassical substitutability and fixed factor proportions. Our concept implies a user cost of labor which consists of the market price of labor plus the costs of inputs associated with the employment of a worker. We present simulation results based on a $\mathrm{CO}_{2}$ tax and the recycling of its revenues to reduce the nonwage labor cost. One simulation is based on the market price of labor and the other on the user cost of labor. We found a double dividend under the first approach but not under the second one.
\end{abstract}

JEL classification: D58, J30, Q25

Keywords: Market-based environmental policy, carbon taxes, double dividend, computable general equilibrium modeling

Correspondence to: Klaus Conrad, Mannheim University, Department of Economics, L7, 3-5, D-68131 Mannheim, Phone: +49 621181 1896, Fax: +49 621181 1893, e-mail: kconrad@rumms.uni-mannheim.de 


\section{Introduction}

Computable general equilibrium (CGE) analyses have played over the last ten years a key role in the evaluation of green tax reforms, the reorientation of the tax system to concentrate taxes more on "bads" like pollution and less on "goods" like labor input or capital formation. The ongoing concern about the magnitude of distortionary taxation suggests the possibility of using environmental taxes to replace existing factor and commodity taxes. A conjecture called the "double dividend hypothesis" points out that environmental taxes have two benefits: they discourage environmental degradation and they raise revenue that could offset other distortionary taxes. ${ }^{1}$ The question in the double dividend debate therefore is whether the internalization of environmental externalities can be beneficial for other policy areas as well since the revenues from pollution taxes could be used to cut other distortionary taxes. The non-environmental dividend can be defined in various ways. Given the important unemployment problem in the EU, priority has been given to the analysis of distortions in the labor market that might explain persisting unemployment. ${ }^{2}$ The revenue from the pollution taxes are recycled to cut labor taxes. On the one side, the narrow base of an energy tax constitutes an inherent efficiency handicap. On the other side, the impact of the tax reform on pre-existing inefficiencies in taxing labor could offset this handicap and a double dividend arises. Therefore, in principle a double dividend can arise only if (i) the pre-existing tax system is significantly inefficient on non-environmental grounds and (ii) the revenue-neutral reform significantly reduces this prior inefficiency. The double dividend actually arises only if the second condition operates with sufficient force. However, it could also arise if the burden of the environmental tax falls mainly on the undertaxed factor (e.g. immobile capital) and relieves the burden of the overtaxed factor labor. ${ }^{3}$ Since no existing tax systems are likely in a second-best optimum, the scope for a double dividend is always present.

Although CGE modeling has provided a number of important insights about the interplay between environmental tax policy and the pre-existing tax system, much remains to be done to improve our understanding of market-based environmental policy. One reason is that some CGE modelers affirm the double dividend hypothesis while others could not find a double dividend outcome. The specification of the labor market, for instance, could be crucial to the discussion on the effect of environmental policy on employment. A labor market policy of recycling tax revenues from an environmental tax to lower employers' non-wage labor cost

\footnotetext{
${ }^{1}$ For a state of the art review on the double dividend issue, see Golder (1997) and Bovenberg and Goulder (2001).

${ }^{2}$ For theoretical papers on the double dividend issue, see Bovenberg and Goulder (1996); Goulder (1995). See Jorgenson and Wilcoxen (1992), Proost and van Regemorter (1995) and Welsch (1996) for empirical papers.

${ }^{3}$ See Bovenberg and Goulder (2001) on this point.
} 
depends on how the labor market is modeled. Non-competitive labor markets could provide another potential channel for a double dividend outcome. In most CGE models the labor market is perfectly competitive and the wage rate adjusts so that supply equals demand.

The objective of this paper is to look at the way, the cost of labor is measured in CGE models. To this end, we use an approach proposed by Conrad (1983) which combines the approaches to neoclassical substitutability and fixed factor proportions. This cost-price approach uses Leontief partially fixed factor proportions to identify both a disposable or variable part and a bound or fixed portion of each input. The true cost, or cost price, of any input consists of its own price plus the costs associated with the portion of that input bound to other inputs. As an example, the cost of an additional worker includes not just salary, but also the costs of inputs tied to the worker (e.g. office equipment, electricity, material, etc.). Within the cost-price framework, the demand for an input can be separated into a committed component linked to the use of other inputs, and a disposable component which is free for substitution. At one extreme, when the disposable quantities of all inputs equal zero, no factor substitution is possible and the cost-price approach reduces to the Leontief fixed-proportion case. At the other extreme, when the committed quantities of all inputs are zero, the neoclassical model is relevant and the cost-price of any input equates the market price. We will econometrically estimate cost share equations in cost-prices and then will use cost prices instead of market prices to investigate the double dividend hypothesis.

The paper is organized as follows. In section 2, we present the cost-price approach and in section 3 the parameter estimates for a restricted version of the manufacturing industry. In section 4 we briefly outline our CGE model. In section 5 we present our simulation results based on a $\mathrm{CO}_{2}$ tax and the recycling of its revenues to reduce the non-wage labor cost. One simulation will be based on market prices and the other one on cost prices. Our objective is to compare the results in the light of the conjecture of a double dividend. The conclusion from our result is summarized in section 6 .

\section{Conditioned input demand and cost share equations in cost-prices}

In contrast to Leontief production functions, we assume that only fractions of the input quantities are related to each other in fixed factor proportions and that therefore, in contrast to the neoclassical theory, only fractions of the input quantities are disposable for substitutions. With capital, labor and energy as inputs, we regard a truck, a truck driver and the minimal possible fuel consumption as bound inputs. In general, however, not the total quantity of an 
input is bound by other inputs with fixed proportions, but a fraction is unbound and disposable for substitution. It is this fraction which is relevant for a reallocation of inputs if relative factor prices change. If the energy price increases, the maintenance of the machinery will be improved (an additional worker), and truck drivers will drive slower (working overtime or less mileage per day). However, this substitution effect can primarily be observed with respect to the unbound component of an input; bound factors like machinery, the stock of trucks, or truck drivers are not objects of a substitution decision; they will be replaced either simultaneously or not at all as one more unit is linked to high costs due to bound inputs (an additional truck requires an additional truck driver). In case of a higher energy price, therefore, the disposable energy input will be the one that will be reduced. The fact that other inputs are bound to energy should be indicated by a cost-price or user cost in which the price of energy enters with an appropriate weight. In order to take into account this aspect, we separate the quantity of an input into a bound part and into an unbound one: ${ }^{4}$

$$
v_{i}=\bar{v}_{i}+\tilde{v}_{i}, \quad i=1, \ldots, n
$$

where $\bar{v}_{i}$ is the number of units of factor $i$ bound by the usage of the remaining $n-1$ inputs, and $\tilde{v}_{i}$ is the disposable quantity of factor $i$. The bound quantity of an input, $\bar{v}_{i}$, depends with fixed factor proportions upon the disposable quantities of the other inputs. Here, $\bar{v}_{i}$ is a simple sum, defined as

$$
\bar{v}_{i}=\sum_{j \neq i} \alpha_{i j} \tilde{v}_{j}, \quad \alpha_{i j} \geq 0 \quad i=1, \ldots, n
$$

where $\alpha_{i j}$ is the quantity of $v_{i}$ bound to one disposable unit of $v_{j}$. Substituting (2) into (1) yields

$$
v_{i}=\sum_{j=1}^{n} \alpha_{i j} \tilde{v}_{j}, \quad \text { where } \alpha_{i i}=1
$$

by definition. If the disposable part of input $j$ is increased by one unit, this increases the total quantity of input $j$ by just this unit and all other inputs $i(i=1, \ldots, n, i \neq j)$ by the quantities $\alpha_{i j}$.

\footnotetext{
${ }^{4}$ For more details see Conrad (1983).
} 
These $\alpha_{i j}$ coefficients constitute a matrix $A=\left(\alpha_{i j}\right)$ which describes the degree of affiliation for any data set. If $\alpha_{i j}=0(i \neq j)$ for all $i$ and $j$, the neoclassical model is relevant and the costprice of any input is its own price. If $\tilde{v}_{i}=0$ ( or $v_{i}=\bar{v}_{i}$ ) for all $i$, no factor substitution is possible and the cost price approach reduces to the Leontief fixed proportion production function.

We next replace the quantities $v_{i}$ in the cost minimizing approach by the partitioning given in (3). Instead of

$$
\min \left\{\sum_{i} P_{i} v_{i} \mid x=H\left(v_{i}, \ldots, v_{n}\right)\right\}
$$

where $x$ is the given output quantity, we write

$$
\min \left\{\sum_{i} P_{i}\left(\sum_{j} \alpha_{i j} \tilde{v}_{j}\right) \mid x=H\left(\sum_{j} \alpha_{1 j} \tilde{v}_{j}, \ldots, \sum_{j} \alpha_{n j} \tilde{v}_{j}\right)\right\}
$$

or

$$
\min \left\{\sum_{j} \tilde{P}_{j} \tilde{v}_{j} \mid x=F\left(\tilde{v}_{1}, \ldots, \tilde{v}_{n}\right)\right\}
$$

where

$$
\tilde{P}_{j}:=\sum_{i} \alpha_{i j} P_{i} \quad \text { and } \quad \alpha_{j j}=1, \quad j=1, \ldots, n
$$

is the cost-price of input $j$. It consists of its own price $\left(P_{j}\right)$ plus the additional costs associated with factors bound to $v_{j}$.

The necessary conditions for a minimum of (5) are

$$
\tilde{P}_{j}=\lambda \cdot F_{\tilde{v}_{j}}, \quad j=1, \ldots, n, \quad x=F\left(\tilde{v}_{1}, \ldots, \tilde{v}_{n}\right)
$$


where $\lambda$ is the Lagrange multiplier. By substituting the cost-minimizing factor demand functions $\tilde{v}_{j}=f_{j}\left(x ; \tilde{P}_{1}, \ldots, \tilde{P}_{n}\right)$ into (3) we obtain the cost-minimizing input quantities in terms of cost prices $\tilde{P}_{1}, \ldots \tilde{P}_{n}$. The dual cost function with respect to the cost prices is then:

$$
C\left(x ; \tilde{P}_{1}, \ldots, \tilde{P}_{n}\right)=\sum_{j} \tilde{P}_{j} \cdot f_{j}\left(x ; \tilde{P}_{1}, \ldots, \tilde{P}_{n}\right)
$$

The analogue to Shephard's lemma (envelope theorem) holds:

$$
\frac{\partial C(x ; \tilde{P})}{\partial \tilde{P}_{i}}=\tilde{v}_{i}
$$

$$
\frac{\partial C(x ; \tilde{P})}{\partial P_{i}}=\sum_{j}\left(\frac{\partial C}{\partial \tilde{P}_{j}}\right)\left(\frac{\partial \tilde{P}_{j}}{\partial P_{i}}\right)=\sum_{j} \alpha_{i j} \cdot \tilde{v}_{j}=v_{i} .
$$

Equations (8) and (9) provide the disposable amounts of each input as well as the cost minimizing quantities of total inputs. From Equation (9), we can determine the cost shares $\left(w_{i}\right)$ of each factor as follows:

$$
w_{i}=\frac{P_{i} \cdot v_{i}}{C}=P_{i}\left(\frac{\partial \ln C(x ; \tilde{P})}{\partial P_{i}}\right) .
$$

These shares equations can then be used to empirically estimate the parameters of the cost prices.

In order to introduce technical change into the cost prices, we adopt the specification proposed by Olson and Shieh (1989):

$$
v_{i}=\sum_{j}\left(\alpha_{i j}+\beta_{i j} \cdot t\right) \tilde{v}_{j}
$$

With this modification Shephard's lemma holds for both $P_{i}$ and $\tilde{P}_{i}$, and it is: 


$$
\frac{\partial C(x ; \tilde{P})}{\partial \tilde{P}_{i}}=\tilde{v}_{i}
$$

$$
\frac{\partial C(x ; \tilde{P})}{\partial P_{i}}=\tilde{v}_{i}+\sum_{j \neq i}\left(\alpha_{i j}+\beta_{i j} \cdot t\right) \tilde{v}_{j}=v_{i}
$$

In the next section, we will estimate econometrically the cost-price model.

\section{Empirical results for a Cobb-Douglas cost function}

As a specification of the cost function we will choose the simplest case, namely a cost function of the Cobb-Douglas type (henceforth CD). However, an approach with cost prices and committed inputs does not result in simple measures of the degree of substitutability as in the conventional CD case where the elasticity of substitution is unity and all inputs are price substitutes. As shown in Conrad (1983), even under the CD-assumption, variable elasticities of substitution and complementary relations are possible. Under our assumption of constant returns to scale and disembodied factor augmenting technical change, $b_{j} \cdot t$, the CD-cost function is:

$$
\ln C(x ; \tilde{P})=\ln x+\alpha_{0}+\sum_{j}\left(\gamma_{j}+b_{j} \cdot t\right) \ln \tilde{P}_{j}
$$

where $\sum_{j} \gamma_{j}=1$ and $\sum_{j} b_{j}=0$. Because of (10),

$$
w_{i}=P_{i}\left\{\sum_{j}\left[\frac{\left(\gamma_{j}+b_{j} \cdot t\right)}{\tilde{P}_{j}}\right]\left(\alpha_{i j}+\beta_{i j} \cdot t\right)\right\}
$$

where

$$
\tilde{P}_{j}=P_{j}+\sum_{k \neq j}\left(\alpha_{k j}+\beta_{k j} \cdot t\right) P_{k}
$$

We have nested the inputs of a sector based on an input-output table with 49 sectors, such that on the first stage the inputs for the CD-production function are capital $K$, labor $L$, electricity $E$, material $M$, and fossil fuel $F$. As data for disaggregated energy inputs are available only for 
a short period of time (1978-90), we are constrained to a pooled time-series cross-section approach. ${ }^{5}$ A total of 49 sectors for which data are available in the German national account statistics are pooled into four sector aggregates:

- $\quad$ the energy supply sectors aggregate

- $\quad$ the energy-intensive manufacturing sectors aggregate

- $\quad$ the non-energy-intensive manufacturing sectors aggregate

- $\quad$ the service sectors aggregate.

The five-equation system, consisting of the five cost-share equations for $K, L, E, M, F$, is estimated for each of the four sector aggregates, employing the panel data set in yearly prices and cost shares. It is assumed that the cost prices are identical in each sector aggregate, i.e. sectoral dummy variables are added only to the coefficients $\gamma_{i}$ in (11).

Due to the high degree of non-linearity inherent in the share equations, we have simplified our approach by concentrating on the cost-price of labor. Hence, the composition (3) is reduced to

$$
K_{i}=\alpha_{K L} \cdot \tilde{L}_{i}+\tilde{K}_{i}, L_{i}=\tilde{L}_{i}, E_{i}=\alpha_{E L} \cdot \tilde{L}_{i}+\tilde{E}_{i}, M_{i}=\alpha_{M L} \cdot \tilde{L}_{i}+\tilde{M}_{i}, F_{i}=\alpha_{F L} \cdot \tilde{L}_{i}+\tilde{F}_{i}
$$

where $i=1,2,3,4$ for the four sector aggregates. The cost-prices for $K, E, F, M$ are therefore market prices, i.e. $\widetilde{P K}_{i}=P K_{i}, \widetilde{P E}_{i}=P E_{i}, \widetilde{P M}_{i}=P M_{i}$ and $\widetilde{P F}_{i}=P F_{i}$. The cost-price of labor is:

$$
\widetilde{P L}_{i}=P L_{i}+\alpha_{K L} \cdot P K_{i}+\alpha_{E L} \cdot P E+\alpha_{F L} \cdot P F_{i}+\alpha_{M L} \cdot P M_{i}
$$

As mentioned before, $\alpha_{i L}, i=K, E, M, F$ are the same for each sector aggregate and so are the technical progress parameters $b_{i}, i=K, L, E, M, F$. We omit technical progress in the cost prices, i.e. $\beta_{i j}=0$ in (11). The system of cost share equations we have to estimate is

\footnotetext{
${ }^{5}$ We are indebted to Henrike Koschel and Martin Falk for providing us with the data set. For more details see Koschel (2001) and Falk and Koebel (1999).
} 


$$
w_{L, i}=\frac{P L_{i} \cdot L_{i}}{C_{i}}=\frac{\left(\gamma_{L_{i}}+b_{L} \cdot t\right) \cdot P L_{i}}{\widehat{P L}_{i}}
$$

$$
w_{K, i}=\frac{P K_{i} \cdot K_{i}}{C_{i}}=\gamma_{K_{i}}+b_{K} \cdot t+\frac{\alpha_{K L} \cdot\left(\gamma_{L_{i}}+b_{L} \cdot t\right) \cdot P K_{i}}{\widetilde{P L}}
$$

$$
w_{E, i}=\frac{P E_{i} \cdot E_{i}}{C_{i}}=\gamma_{E_{i}}+b_{E} \cdot t+\frac{\alpha_{E L} \cdot\left(\gamma_{L_{i}}+b_{L} \cdot t\right) P E_{i}}{\widetilde{P L}}
$$

$$
w_{M, i}=\frac{P M_{i} \cdot M_{i}}{C_{i}}=\gamma_{M_{i}}+b_{M_{i}} \cdot t+\frac{\alpha_{M L}\left(\gamma_{L_{i}}+b_{L} \cdot t\right) P M_{i}}{\widetilde{P L}_{i}}
$$

$$
w_{F, i}=\frac{P F_{i} \cdot F_{i}}{C_{i}}=\gamma_{F_{i}}+b_{F} \cdot t+\frac{\alpha_{F L}\left(\gamma_{L_{i}}+b_{L} \cdot t\right) P F_{i}}{\widetilde{P L}}
$$

with $\widetilde{P L}_{i}$ as given in (13). In addition to using nonlinear techniques, the cost price model must be estimated with non-negativity constraints imposed on the parameters $\alpha_{i L}, i=K, E, M$, $F$. Table 1 presents the estimated parameters.

Table 1: Maximum likelihood estimates for the parameters of the cost-prices and of technical change (asymptotic $t$-ratios in parentheses)

$\begin{array}{lcccccccc}\gamma_{K} & 0.092 & (17.173) & b_{K} & 8.5 \cdot 10^{-4} & (0,935) & \alpha_{K L} & 0.002 & (0,431) \\ \gamma_{L} & 0.458 & (11.340) & b_{L} & -0.005 & (-1,824) & \alpha_{E L} & 0.055 & (2,611) \\ \gamma_{E} & 4 \cdot 10^{-8} & \left(6 \cdot 10^{-6}\right) & b_{E} & 4.2 \cdot 10^{-4} & (1,889) & \alpha_{F L} & 0.072 & (2,993) \\ \gamma_{F} & 0.048 & (3.508) & b_{F} & -0.002 & (-1,143) & \alpha_{M L} & 0.422 & (3,128) \\ \gamma_{M}{ }^{*} & 0.402 & - & b_{M}{ }^{*} & 0.006 & - & & & \end{array}$

Log Likelihood $=3540.189$

Observations: 637

* As the error terms add to zero, they are stochastically dependent and we have omitted equation (17) for estimation. 
The bias of technical change is capital, electricity and material using $\left(b_{K}>0, b_{E}>0, b_{M}>0\right)$, and labor and fossil fuel saving $\left(b_{L}<0, b_{F}<0\right)$. The cost price of labor (13) for the industry with the dummy variable of zero is

$$
\widetilde{P L}=P L+0.002 \cdot P K+0.055 \cdot P E+0.422 \cdot P M+0.072 \cdot P F
$$

Using the $\alpha_{i L}$ parameter estimates in Table 1, we conclude from (12) that an additional unit of labor needs 0.002 units of capital, 0.055 units of electricity, 0.422 units of material and 0.072 units of fossil fuel. In other words, reducing labor input by one unit will release 0.002 units of capital, 0.055 units of electricity, 0.422 units of material and 0.072 units of fossil fuel for

possibilities of substitution as the disposable components $\tilde{K}, \tilde{E}, \tilde{M}, \tilde{F}$ increase with the reduction of $L(=\tilde{L})$. In the next section we will use committed inputs, disposable inputs, and the corresponding cost-price of labor within the framework of a CGE model to investigate their impact on the outcome of the double dividend conjecture.

\section{The features of the CGE model}

This section presents the main characteristics of a comparative-static multi-sector model for the German economy designed for the medium-run economic analysis of carbon abatement constraints. The concrete specification of the model covers seven sectors and two factors. The choice of production sectors captures key dimensions in the analysis of greenhouse gas abatement, such as differences in carbon intensities and the scope for substitutability across energy goods and carbon-intensive non-energy goods. The energy goods identified in the model are coal (COL), natural gas (GAS), crude oil (CRU), refined oil products (OIL) and electricity (ELE). Non-energy production consists of an aggregate energy-intensive sector (EIS) and the rest of production (OTH). Primary factors include labor and capital, which are both assumed to be intersectorally mobile. Table 2 summarizes the sectors and primary factors incorporated in the model. 
Table 2: Overview of sectors and factors

\begin{tabular}{|c|c|c|c|c|c|}
\hline \multicolumn{4}{|c|}{ Sectors } & \multicolumn{2}{|c|}{ Primary factors } \\
\hline 1 & $\mathrm{COL}$ & Coal & & CAP & Capital - K \\
\hline 2 & OIL & Refined oil products & $-\mathrm{F}$ & $\mathrm{LAB}$ & Labor $-\mathrm{L}$ \\
\hline 3 & GAS & Natural gas & & & \\
\hline 4 & ELE & Electricity & $-\mathrm{E}$ & & \\
\hline 5 & CRU & Crude oil & & & \\
\hline 6 & EIS & Energy-intensive sectors & $-\mathrm{M}$ & & \\
\hline 7 & $\mathrm{OTH}$ & Rest of industry & & & \\
\hline
\end{tabular}

The model is a well-known Arrow-Debreu model that concerns the interaction of consumers and producers in markets. Market demands are the sum of final and intermediate demands. Final demand for goods and services is derived from the utility maximization of a representative household subject to a budget constraint. In our comparative-static framework, overall investment demand is fixed at the reference level. The consumer is endowed with the supply of the primary factors of production (labor and capital) and tax revenues (including $\mathrm{CO}_{2}$ taxes). Household preferences are characterized by an aggregate, hierarchical (nested) constant elasticity of substitution (CES) utility function. It is given as a CES composite of an energy aggregate and a non-energy consumption composite. Substitution patterns within the energy aggregate and the non-energy consumption bundle are reflected via Cobb-Douglas functions. Producers choose input and output quantities in order to maximize profits. Figure 1 illustrates the nested structure in production. At the top level, we have the KLEMF-structure with the CD specification in cost-prices. At the second level, a CES function describes the substitution possibilities between the material components. The primary energy composite is defined as a CES function of coal, oil and natural gas. Key substitution elasticities are given in the Appendix.

The government distributes transfers and provides a public good (including public investment) which is produced with commodities purchased at market prices. In order to capture the implications of an environmental tax reform on the efficiency of public fund raising, the model incorporates the main features of the German tax system: income taxes including social insurance contributions, capital taxes (corporate and trade taxes), value-added taxes, and other indirect taxes (e.g. mineral oil tax). 


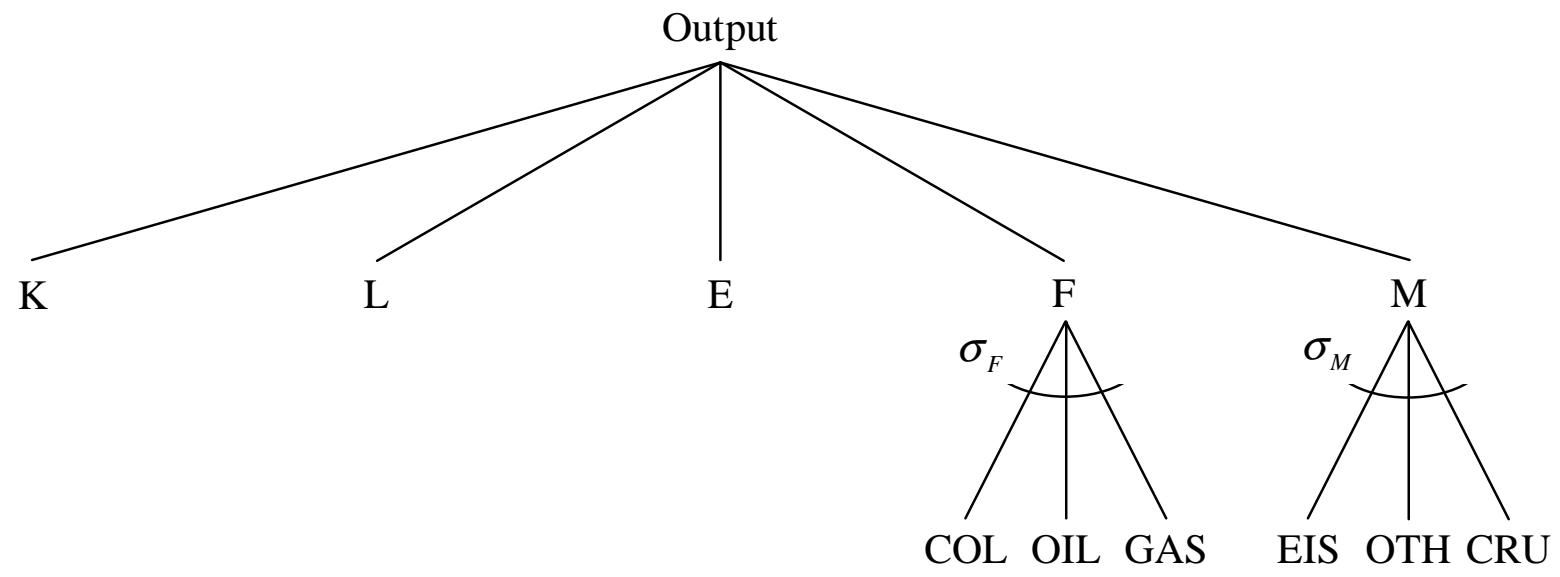

Figure 1: $\quad$ Nested structure of production

All commodities are traded internationally. We adopt the Armington assumption that goods produced in different regions are qualitatively distinct for all commodities. There is imperfect transformability (between exports and domestic sales of domestic output) and imperfect substitutability (between imports and domestically sold domestic output). On the output side, two types of differentiated goods are produced as joint products for sale in the domestic markets and the export markets respectively. The allocation of output between domestic sales and international sales is characterized by a constant elasticity of transformation (CET) function. Intermediate and final demands are (nested CES) Armington composites of domestic and imported varieties. Germany is assumed to be a price-taker with respect to the rest of the world (ROW), which is not explicitly represented as a region in the model. Trade with ROW is incorporated via perfectly elastic ROW import-supply and exportdemand functions. There is an imposed balance-of-payment constraint to ensure trade balance between Germany and the ROW. That is, the value of imports from ROW to Germany must equal the value of exports to ROW after including a constant benchmark trade surplus (deficit).

The analysis of the employment effects associated with an environmental tax reform requires the specification of unemployment. In our formulation, we assume that unemployment is caused by a rigid and too high consumer wage (see, for example, Bovenberg and van der Ploeg 1996).

For each input structure of the industries, we choose the KLEMF-model at the top level. We employ in the cost share equations and in the cost price of labor the parameters, estimated from another source of input-output tables. Since the cost shares within the six industries differ from the cost shares calculated in the econometric part, we have to calibrate 
one parameter per cost share in order to adjust the estimated cost shares to the observed ones in the 7-industry base year table. Therefore, $\gamma_{L_{i}}(i=1, \ldots, 7)$ follows from (14), given the cost shares of the 7-industry table. If $\gamma_{L_{i}}$ is determined, $\gamma_{K_{i}}, \gamma_{E_{i}}, \gamma_{F_{i}}$ and $\gamma_{M_{i}}$ can be calculated from $(15)-(18)$.

Allen elasticities $\left(\sigma_{i j}\right)$ for the Cobb-Douglas function in cost prices in the CGE model in each sector are given by

$$
\sigma_{i j}=1-\frac{P_{i} \cdot P_{j}}{w_{i} \cdot w_{j}} \cdot\left[\sum_{k} \frac{\left(\gamma_{k}+b_{k} \cdot t\right) \cdot \alpha_{i k} \cdot \alpha_{j k}}{\widetilde{P}_{k}^{2}}\right] \quad i, j, k=\mathrm{K}, \mathrm{L}, \mathrm{E}, \mathrm{F}, \mathrm{M}
$$

Allen elasticities are related to the price elasticities of demand for factors of production $\left(\varepsilon_{i j}\right)$

$$
\varepsilon_{i j}=\sigma_{i j} \cdot w_{j} \quad i, j=\mathrm{K}, \mathrm{L}, \mathrm{E}, \mathrm{F}, \mathrm{M}
$$

Table 3 presents Allen elasticities and price elasticities of demand in the CGE model with the parameter estimates of the cost-price model. Capital is a substitute for all inputs with an elasticity of substitution close to one. Electricity and fossil fuel have a complementary relationship to labor; material is a substitute for labor, for electricity and for fossil fuel; electricity and fossil fuel are complements in the non-energy intensive industries (OTH).

The disposable quantities of each factor of production can be derived from equation (12). The disposable quantity of material, for instance, is

$$
\widetilde{M}_{i}=M_{i}-a_{M L} \cdot L_{i} \quad i=1,2, \ldots, 7
$$

From Table 4 we observe that in the non-energy-intensive industries 82 percent of electricity is bound to labor whereas in the energy intensive industries (EIS) only 16 percent are bound to labor; i.e. up to 84 percent are either bound to capital or disposable for substitution. For materials, $13 \%$ of this input in the sector OTH is bound to labor and 87 percent is free for substitution. In the industry EIS only 6 percent is linked to labor and 94 percent is substitutable. Similarly as for electricity, a high percentage of fossil fuel (96 percent) is linked to labor in the industry OTH and only 22 percent in the energy intensive industry EIS. In this industry, about 80 percent of fossil fuel is a candidate for substitution, whereas in other industries (OTH) only 4 percent is such a candidate. 
Table 3: $\quad$ Allen elasticities of substitution and price elasticities of demand

\begin{tabular}{lrrrrr}
\hline Sector & OTH & EIS & & OTH & EIS \\
\hline$\sigma_{K L}$ & 0.996 & 0.993 & $\varepsilon_{K L}$ & 0.153 & 0.097 \\
$\sigma_{K E}$ & 0.997 & 0.999 & $\varepsilon_{K E}$ & 0.011 & 0.036 \\
$\sigma_{K M}$ & 0.999 & 0.999 & $\varepsilon_{K M}$ & 0.489 & 0.647 \\
$\sigma_{K F}$ & 0.996 & 0.998 & $\varepsilon_{K F}$ & 0.011 & 0.032 \\
$\sigma_{L E}$ & -2.181 & 0.009 & $\varepsilon_{L K}$ & 0.333 & 0.185 \\
$\sigma_{L M}$ & 0.444 & 0.580 & $\varepsilon_{L E}$ & -0.024 & 0.0003 \\
$\sigma_{L F}$ & -3.035 & -0.432 & $\varepsilon_{L M}$ & 0.217 & 0.375 \\
$\sigma_{E M}$ & 0.579 & 0.937 & $\varepsilon_{L F}$ & -0.035 & -0.014 \\
$\sigma_{E F}$ & -2.053 & 0.786 & $\varepsilon_{E K}$ & 0.334 & 0.187 \\
$\sigma_{M F}$ & 0.466 & 0.909 & $\varepsilon_{E L}$ & -0.334 & 0.001 \\
$\varepsilon_{K K}$ & -0.664 & -0.812 & $\varepsilon_{E M}$ & 0.283 & 0.607 \\
$\varepsilon_{L L}$ & -0.491 & -0.547 & $\varepsilon_{E F}$ & -0.024 & 0.025 \\
$\varepsilon_{E E}$ & -0.259 & -0.820 & $\varepsilon_{M K}$ & 0.335 & 0.187 \\
$\varepsilon_{M M}$ & -0.414 & -0.306 & $\varepsilon_{M L}$ & 0.068 & 0.056 \\
$\varepsilon_{F F}$ & -0.073 & -0.761 & $\varepsilon_{M E}$ & 0.006 & 0.034 \\
& & & $\varepsilon_{M F}$ & 0.005 & 0.029 \\
& & & $\varepsilon_{F K}$ & 0.333 & 0.186 \\
& & & $\varepsilon_{F L}$ & -0.465 & -0.042 \\
& & & $\varepsilon_{F E}$ & -0.023 & 0.028 \\
& & & $\varepsilon_{F M}$ & 0.228 & 0.589 \\
\hline
\end{tabular}

* The calibrated parameters are $\gamma_{L_{E I S}}=0.151$ and $\gamma_{L_{O T H}}=0.238$. The benchmark value shares for Germany are $w_{K, E I S}=0.187, w_{L, E I S}=0.097, w_{E, E I S}=0.036, w_{M, E I S}=0.648, w_{F, E I S}=0.032, w_{K, \text { OTH }}=0.335, w_{L, \text { OTH }}=$ $0.153, w_{\text {E, ОTН }}=0.011, w_{M, \text { ОтН }}=0.489$ and $w_{F, \text { ОTH }}=0.011$.

Table 4: Disposable and bounded fraction of each factor of production in the CGE model

\begin{tabular}{lcccc}
\hline & \multicolumn{2}{c}{ Disposable } & \multicolumn{2}{c}{ Bound (to labor) } \\
& OTH & EIS & OTH & EIS \\
\hline K & 0.999 & 0.999 & 0.001 & 0.001 \\
L & 1 & 1 & 0 & 0 \\
E & 0.185 & 0.841 & 0.815 & 0.159 \\
M & 0.868 & 0.937 & 0.132 & 0.063 \\
F & 0.040 & 0.784 & 0.960 & 0.216 \\
\hline
\end{tabular}


Under constant returns to scale and price-taking behavior, the price of an industry $j$, $P_{j}$, is equal to its unit cost:

$$
P_{j}=c_{j}\left(P K, \widetilde{P L}_{j}, P E, P M_{j}, P F_{j}\right)
$$

Written in logarithmic terms, using our CD specification in cost-prices, we obtain

$$
\begin{aligned}
\ln P_{j} & =\left(\gamma_{K_{j}}+\beta_{K} \cdot t\right) \ln P K+\left(\gamma_{L_{j}}+\beta_{L} \cdot t\right) \ln \widetilde{P L}_{j}+\left(\gamma_{E_{j}}+\beta_{E} \cdot t\right) \ln P E \\
& +\left(\gamma_{M_{j}}+\beta_{M} \cdot t\right) \ln P M_{j}\left(P_{5}, P_{6}, P_{7}\right)+\left(\gamma_{F_{j}}+\beta_{F} \cdot t\right) \ln P F_{j}\left(P_{1}, P_{2}, P_{3}\right) .
\end{aligned}
$$

In addition, we have unit cost functions of the CES type for material and for fossil fuel:

$$
\begin{array}{ll}
P M_{j}=f_{j}\left(P_{5}, P_{6}, P_{7}\right) & j=1,2, \ldots 7 \\
P F_{j}=f_{j}\left(P_{1}, P_{2}, P_{3}\right) & j=1,2, \ldots 7
\end{array}
$$

In order to solve the price system $P_{1}, \ldots, P_{7}$, we have to add the labor-cost price equations (13), where $P L_{j}=P L$ for all $j$. If the price system has been solved, next price dependent inputoutput coefficients as derived input demand functions can be determined and the sectoral output levels can finally be calculated. A detailed description of the model is given in the Appendix. The main data source underlying the model is the GTAP version 4 database, which represents global production and trade data for 45 countries and regions, 50 commodities and 5 primary factors (McDougall et al. 1998). In addition, we use OECD/IEA energy statistics (IEA, 1996) for 1995. Reconciliation of these data sources yields the benchmark data of our model. 


\section{Empirical results}

In our simulation, we distinguish two types of scenarios. In each simulation, carbon taxes are levied in order to meet a 21 percent reduction of domestic carbon dioxide emissions as compared to 1990 emission levels. This is the reduction target the German government has committed itself to in the EU Burden Sharing Agreement adopted at the environmental Council meeting by Member States on June 1998. One type of simulation is based on the market price of labor and the second type on the cost price of labor. We impose revenueneutrality in the sense that the level of public provision is fixed. Subject to this equal-yield constraint, we consider to ways to recycle the $\mathrm{CO}_{2}$ tax revenue for each type of simulation. One way is to recycle it by a lump-sum transfer (LS) to the representative household. The other way is to adopt an environmental tax reform (ETR) in view of the adverse employment effects of carbon emission constraints. In such a case, the tax revenue is used to lower the non-wage labor costs (social insurance payment). Table 5 summarizes the implications of the two types of simulation studies under two ways of recycling the tax revenues. If firms decide on production and substitution on the base of the market price of labor and the tax revenue is recycled by a lump-sum transfer, then employment rate will be lower by 0.15 percent (see column 1 in Table 5). Welfare, expressed here as a change in GDP, will be lower by 0.55 percent. The $\mathrm{CO}_{2}$ tax rate at the 21 percent $\mathrm{CO}_{2}$ reduction level (marginal abatement cost) is 13.9 US\$ per ton. Production in all industries declines, proceeded by a lower demand for labor. If the tax revenue is used to lower non-wage labor costs, we obtain an employment dividend because employment increases by 0.43 percent. Since GDP does not increase (-0.38 percent), we do not obtain a "strong double dividend" where the level of emissions is reduced and employment and GDP are increased from the tax reform by itself. The positive substitution effect on labor from the ETR outweighs the negative output effect on labor. For the producer, the price of labor is lower by 0.72 percent compared to the policy of a lumpsum transfer (last rows in Table 5). The prices $P F$ of fossil fuel have increased by the $\mathrm{CO}_{2}$ tax, and this increase differs by industry according to the size and composition of this input.

The results under the user cost (cost-price) concept of labor can be explained best by comparing the change of the market price of labor with the change of the user cost of labor after the ETR. From the producer's point of view, the price of labor declined by 0.72 percent after the ETR but only by about 0.59 percent under the user cost concept. As the second half of Table 5 shows, the cost-price of labor differs by industry because the price aggregates $P M$ and $P F$ in (19) differ by industry. ${ }^{6}$ Since direct wage costs are only about two-thirds of the

\footnotetext{
${ }^{6}$ The cost-price approach has not been adopted for the industries coal, crude oil, and gas.
} 
user cost of labor, the reduction in the cost of labor from the cut in social insurance payments is smaller under the cost-price concept. Hence, the substitution effect on labor is weaker and is outweighed by the negative output effect from higher energy prices (lower GDP). Therefore, we do not obtain a double dividend under the cost-price concept. The higher price

$\widetilde{P L}$ from (19) (about 1.55) is not the reason for this result, because this figure is taken into account when calibrating the parameters. The crucial impact comes from the aspect that a higher price of energy also raises the cost-price of labor because workers need energy in order to be productive. Therefore, employment declines more under the cost-price approach than under the market price approach $(-0.55$ versus -0.15 percent $)$. When the tax revenue is recycled, the firm perceives a reduction of the cost-price by 0.59 percent on the average to small in order to induce a substitution process high enough to yield a double dividend. Although the decline in GDP is less under the cost-price approach than under the market price approach $(-0.22$ versus -0.38 percent $)$, the incentive for substitution is weaker under the cost price approach and therefore employment declines ( -0.06 versus 0.43 percent).

\section{Conclusion}

Policy makers are used to an economist's advice that the outcome of a policy is ambiguous and depends on assumptions made. This fact makes our consulting work not very attractive. However, we think that our point that user costs of labor matter more than the normal wage costs is intuitively attractive when arguing about the double dividend hypothesis. 
Table 5: Empirical results (LS - lump-sum transfer, ETR - environmental tax reform)

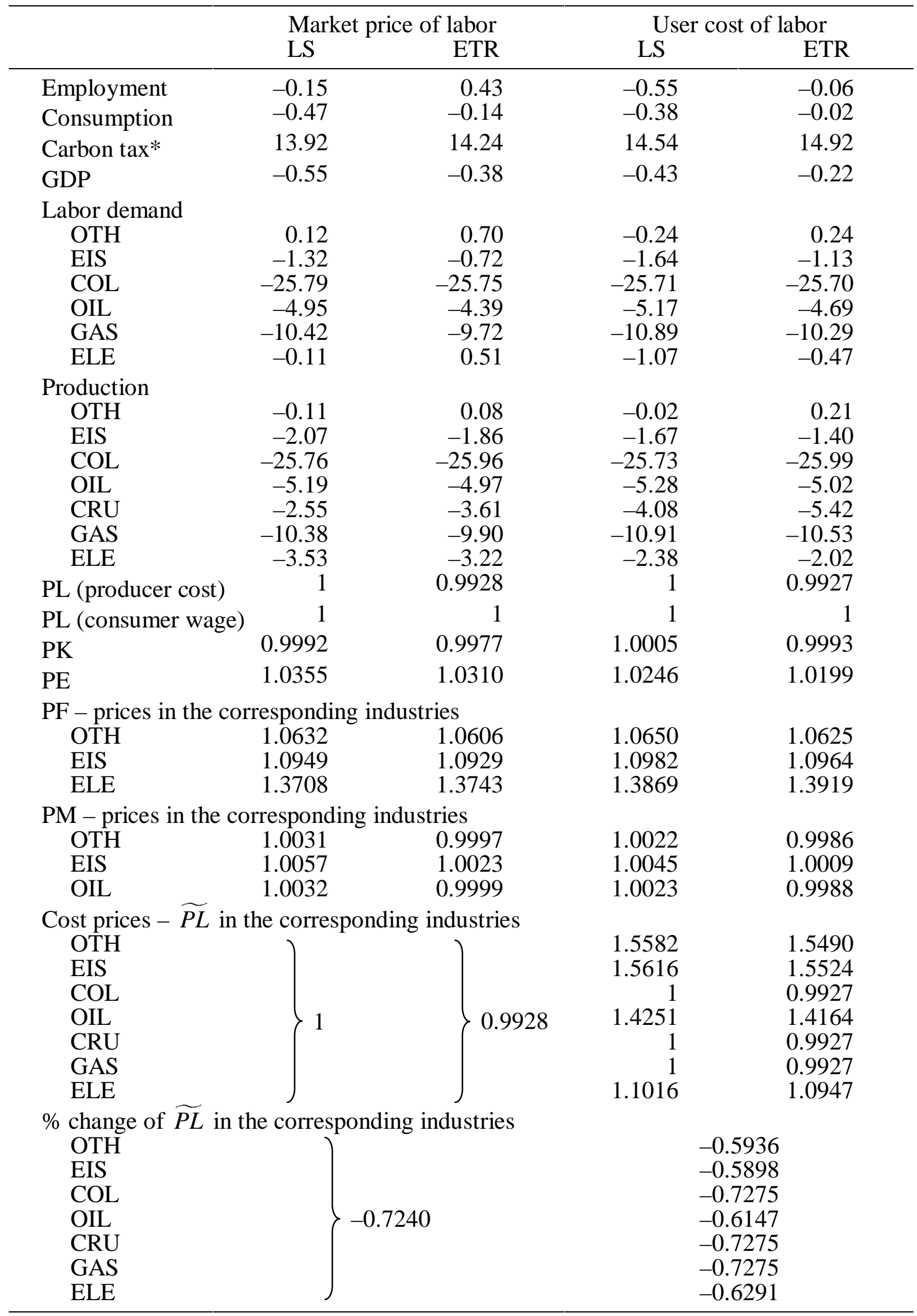

* In US\$. All other figures are percentage values or price indices. 


\section{References}

Bovenberg, A.L. and L.H. Goulder, Optimal Environmental Taxation in the Presence of Other Taxes: General Equilibrium Analysis, American Economic Review, 86, 4, 985-1000,1996.

Bovenberg, A.L. and L.H. Goulder, Environmental Taxation and Regulation in a Second-Best Setting, in: Handbook of Public Economics, 2. ed., A. Auerbach and M. Feldstein (eds.), North Holland, 2001.

Bovenberg, A.L. and F. van der Ploeg, Optimal Taxation, Public Goods and Environmental Policy with Involuntary Unemployment, Journal of Public Economics, 62, 59-83, 1996.

Conrad, K., Cost Prices and Partially Fixed Factor Proportions in Energy Substitution, European Economic Review, 21, 299-312, 1983.

Conrad, K., Computable General Equilibrium Models for Environmental Economics and Policy Analysis, in: J. van den Bergh (ed.), The Handbook of Environmental and Resource Economics, Edward Elgar Publishing Comp., 1999.

Falk, M. and B.M. Koebel, Curvature Conditions and Substitution Pattern among Capital, Energy, Material and Heterogeneous Labor, Discussion Paper No. 99-06, ZEW, Mannheim, 1999.

Ferris, M.C. and T.S. Munson, Complementarity Problems in GAMS and the PATH Solver, Journal of Economic Dynamics and Control, 24 (2), 165-188, 2000.

Goulder, L.H., Effects of Carbon Taxes in an Economy with Prior Tax Distortions: An Intertemporal General Equilibrium Analysis, Journal of Environmental Economics and Management, 29, 271-297, 1995.

Goulder, L.H., Environmental Taxation in a Second-Best World, in H. Folmer and T. Tietenberg (eds.), The International Yearbook of Environmental and Resource Economics, Edward Elgar, Chaltenham, 1997.

IEA (International Energy Agency), Energy Prices and Taxes, Energy Balances of OECD and Non-OECD-countries; IEA publications: Paris, 1996.

Jorgenson, D.W. and P.J. Wilcoxen, Reducing U.S. Carbon Dioxide Emissions: The Cost of Different Goals, in: J.R. Moroney (ed.), Energy, Growth, and Environment: Advances in the Economics of Energy and Resources, 7, JAI Press, 125-158, 1992.

Koschel, H., A CGE-Analysis of the Employment Double Dividend Hypothesis, Diss. University of Heidelberg, 2001.

McDougall R.A., Elbehri A. and T.P. Truong, Global trade, Assistance and Protection: The GTAP 4 Data Base; Center for Global Trade Analysis, Purdue University: West Lafayette, 1998. 
Olson, D.O. and Y.-N. Shieh, Estimating Functional Forms in Cost-Prices, European Economic Review, 33, 1445-1461, 1989.

Proost, S. and D. van Regemorter, The Double Dividend and the Role of Inequality Aversion and Macroeconomic Regimes, International Tax and Public Finance, 2, 207-219, 1995.

Welsch, H., Recycling of Carbon/Energy Taxes and the Labor Market - A General Equilibrium Analysis for the European Community, Environmental and Resource Economics, 8, 141-155, 1996.

Yen, S.T., Estimating Functional Forms in Cost-Prices - A Comment, European Economic Review, 37, 203-208, 1993. 


\section{Appendix}

The appendix provides an algebraic summary of the comparative-static model. It is formulated as a mixed-complementarity problem (MCP) using the General Algebraic Modeling System (GAMS) (Ferris and Munson 2000). In this approach, four classes of equilibrium conditions characterize an economic equilibrium: zero-profit conditions for constant-returns-to-scale production activities, market clearance conditions for each primary factor and produced good, income definitions for the economic agents, and auxiliary equations (equal yield constraints). The fundamental unknowns of the system are activity levels, market prices, income levels and auxiliary variables. The zero profit conditions exhibit complementary slackness with respect to associated activity levels, the market clearance conditions with respect to market prices, the income definition equations with respect to the incomes of the economic agents, and the auxiliary equations with respect to the auxiliary variables. The orthogonality symbol, $\perp$, associates the variables for the complementary slackness conditions. Differentiating profit and expenditure functions with respect to input and output prices provides compensated demand and supply coefficients (Hotelling's lemma), which appear subsequently in the market clearance conditions. An equilibrium allocation determines production levels, prices, incomes and auxiliary variables. Table A1 explains the notations for variables and parameters. Table A2 gives key substitution elasticities.

\section{Zero profit conditions}

$$
\begin{aligned}
& {\left[\mathrm{b}_{1} \cdot P_{i}^{1+\varepsilon}+\mathrm{b}_{2} \cdot P F X^{1+\varepsilon}\right]^{\frac{1}{1+\varepsilon}}=P K^{\gamma_{K_{i}}} \cdot \widetilde{P L}_{i}^{\gamma_{L_{i}}} \cdot P E^{\gamma_{E_{i}}} \cdot P M_{i}^{\gamma_{M_{i}}} \cdot P F_{i}^{\gamma_{F_{i}}} \quad \perp Y_{i}} \\
& \text { with } \widetilde{P L}_{i}=P L+\alpha_{K L} \cdot P K+\alpha_{E L} \cdot P E+\alpha_{M L} \cdot P M_{i}+\alpha_{F L} \cdot P F_{i} \text {, } \\
& P M_{i}=\left[\sum_{j=4}^{6} \mathrm{c}_{i j}^{\sigma_{M}} \cdot P A_{j}^{1-\sigma_{M}}\right]^{\frac{1}{1-\sigma_{M}}}, P F_{i}=\left[\sum_{j=1}^{3} \mathrm{~d}_{i j}^{\sigma_{F}} \cdot P A_{j}^{1-\sigma_{F}}\right]^{\frac{1}{1-\sigma_{F}}}
\end{aligned}
$$

$$
P A_{i}=\left[\mathrm{e}_{1}^{\sigma_{A}} \cdot P_{i}^{1-\sigma_{A}}+\mathrm{e}_{2}^{\sigma_{A}} \cdot P F X^{1-\sigma_{A}}\right]^{\frac{1}{1-\sigma_{A}}}+\mathrm{a}_{i}^{C O} \cdot P C O
$$

$$
P C=\left[\mathrm{f}_{1}^{\sigma_{C}} \cdot\left(\prod_{i=1}^{4} P A_{i}^{\mathrm{g}_{1 i}}\right)^{1-\sigma_{C}}+\mathrm{f}_{2}^{\sigma_{C}} \cdot\left(\prod_{j=5}^{7} P A_{j}^{\mathrm{g}_{2 j}}\right)^{1-\sigma_{C}}\right]^{\frac{1}{1-\sigma_{C}}}
$$

A.4) $\left.\quad P Z=\left(\sum_{\mathrm{i}=1}^{3} \mathrm{~h}_{1 i}^{\sigma_{G}} \cdot P A_{i}^{1-\sigma_{G}}\right)^{1-\Sigma_{\mathrm{j}} \mathrm{h}_{2 j}}\right)^{1-\sigma_{G}} \cdot \prod_{j=4}^{7} P A_{j}^{\mathrm{h}_{2 j}}$ 
Input and output coefficients

$$
\mathrm{a}_{i}^{K}=w_{K, i} \cdot \frac{\left[\mathrm{b}_{1} \cdot P_{i}^{1+\varepsilon}+\mathrm{b}_{2} \cdot P F X^{1+\varepsilon}\right]^{\frac{1}{1+\varepsilon}}}{P K}
$$

$$
\mathrm{a}_{i}^{L}=\gamma_{L, i} \cdot \frac{\left[\mathrm{b}_{1} \cdot P_{i}^{1+\varepsilon}+\mathrm{b}_{2} \cdot P F X^{1+\varepsilon}\right]^{\frac{1}{1+\varepsilon}}}{\widehat{P L}_{i}}
$$

(A.7)

$$
\mathrm{a}_{j i}^{Y}=w_{F, i} \cdot \frac{\left[\mathrm{b}_{1} \cdot P_{i}^{1+\varepsilon}+\mathrm{b}_{2} \cdot P F X^{1+\varepsilon}\right]^{\frac{1}{1+\varepsilon}}}{P F_{i}} \cdot\left(\frac{\mathrm{d}_{i j} \cdot P F_{i}}{P A_{j}}\right)^{\sigma_{F}} \quad j=1,2,3
$$

$$
\mathrm{a}_{j i}^{Y}=w_{E, i} \cdot \frac{\left[\mathrm{b}_{1} \cdot P_{i}^{1+\varepsilon}+\mathrm{b}_{2} \cdot P F X^{1+\varepsilon}\right]^{\frac{1}{1+\varepsilon}}}{P E} \quad j=4
$$

$$
\mathrm{a}_{j i}^{Y}=w_{M, i} \cdot \frac{\left[\mathrm{b}_{1} \cdot P_{i}^{1+\varepsilon}+\mathrm{b}_{2} \cdot P F X^{1+\varepsilon}\right]^{\frac{1}{1+\varepsilon}}}{P M_{i}} \cdot\left(\frac{\mathrm{c}_{i j} \cdot P M_{i}}{P A_{j}}\right)^{\sigma_{M}} \quad j=5,6,7
$$

(A.8) $\quad \mathrm{a}_{j}^{C}=\mathrm{f}_{1}^{\sigma_{C}} \cdot P C^{\sigma_{C}} \cdot \mathrm{g}_{1 j} \cdot\left(\prod_{i=1}^{4} P A_{i}^{\mathrm{g}_{1 i}}\right)^{1-\sigma_{C}} / P A_{j} \quad j=1,2,3,4$

$$
\mathrm{a}_{j}^{C}=\mathrm{f}_{2}^{\sigma_{C}} \cdot P C^{\sigma_{C}} \cdot \mathrm{g}_{2 j} \cdot\left(\prod_{i=5}^{7} P A_{i}^{\mathrm{g}_{2 i}}\right)^{1-\sigma_{C}} / P A_{j} \quad j=5,6,7
$$

(A.9)

$$
\begin{array}{ll}
\mathrm{a}_{j}^{Z}=\left(1-\sum_{\mathrm{i}=4}^{7} \mathrm{~h}_{2 i}\right) \cdot P Z \cdot\left(\frac{\mathrm{h}_{1 j}}{P A_{j}}\right)^{\sigma_{G}} /\left(\sum_{\mathrm{i}=1}^{3} \mathrm{~h}_{1 i}^{\sigma_{G}} \cdot P A_{i}^{1-\sigma_{G}}\right) & j=1,2,3 \\
\mathrm{a}_{j}^{Z}=\mathrm{h}_{2 j} \cdot \frac{P Z}{P A_{j}} & j=4,5,6,7
\end{array}
$$

(A.10) $\mathrm{a}_{i}^{H}=\left(\frac{\mathrm{e}_{1} \cdot P A_{i}}{P_{i}}\right)^{\sigma_{A}}, \mathrm{a}_{i}^{M}=\left(\frac{\mathrm{e}_{1} \cdot P A_{i}}{P F X}\right)^{\sigma_{A}}$

(A.11) $\quad \mathrm{a}_{i}^{D}=\left[P_{i} /\left(\mathrm{b}_{1} \cdot P_{i}^{1+\varepsilon}+\mathrm{b}_{2} \cdot P F X^{1+\varepsilon}\right)^{\frac{1}{1+\varepsilon}}\right]^{\varepsilon}, \mathrm{a}_{i}^{X}=\left[P F X /\left(\mathrm{b}_{1} \cdot P_{i}^{1+\varepsilon}+\mathrm{b}_{2} \cdot P F X^{1+\varepsilon}\right)^{\frac{1}{1+\varepsilon}}\right]^{\varepsilon}$

Market clearance conditions
(A.12) $\bar{K}=\sum_{i} \mathrm{a}_{i}^{K} \cdot Y_{i}$
$\perp P K$
(A.13) $\quad \mathrm{U} \equiv \overline{\mathrm{L}}-\sum_{\mathrm{i}} \mathrm{a}_{i}^{L} \cdot Y_{i}$
(A.14) $\overline{C O}=\sum_{i} \mathrm{a}_{i}^{C O} \cdot A_{i}$
$\perp P C O$
(A.15) $\quad \mathrm{a}_{i}^{D} \cdot Y_{i}=\mathrm{a}_{i}^{H} \cdot A_{i}$
$\perp P_{i}$ 
(A.16) $\quad A_{i}=\sum_{j} \mathrm{a}_{i j}^{A} \cdot Y_{j}+\mathrm{a}_{i}^{I} \cdot \bar{I}+\mathrm{a}_{i}^{C} \cdot C+\mathrm{a}_{i}^{Z} \cdot Z$

(A.17) $\quad \sum_{i} P F X \cdot \mathrm{a}_{i}^{X} \cdot Y_{i}=\sum_{i} P F X \cdot \mathrm{a}_{i}^{M} \cdot A_{i}+D$

(A.18) $\quad C=\frac{M_{R A}}{P C}$

(A.19) $Z=\frac{M_{G}}{P Z}$

Income definitions

(A.20) $\quad M_{R A}=\left(1-t \cdot \tau_{E T R}\right) \cdot P L \cdot \sum_{i} \mathrm{a}_{i}^{L} \cdot Y_{i}+(1-t) \cdot P K \cdot \bar{K}$

$$
-P I \cdot \bar{I}-P C \cdot D+\tau_{L S} \cdot T R
$$

with $P I=\left[\sum_{i=1}^{7} \mathrm{a}_{i}^{I} \cdot P A_{i}\right]$

(A.21) $\quad M_{G}=P C O \cdot \overline{C O}+t \cdot \tau_{E T R} \cdot P L \cdot \sum_{i} \mathrm{a}_{i}^{L} \cdot Y_{i}+t \cdot P K \cdot \bar{K}-\tau_{L S} \cdot T R \quad \perp M_{G}$

Auxiliary equation
(A.22) $\quad \bar{Z}=Z$
$\perp \tau_{L S}, \tau_{E T R}$

Table A1: Sets, activity and price variables, endowments

Sets

$i, j$

Sectors and goods (7 commodities)

Activity variables

$Y_{i}$

$A_{i}$

C

Z

U

Price variables

$P_{i}$

$P A_{i}$

$P E$

$P M_{i}$

$P F_{i}$

PI

$P F X$
Aggregate production

Armington aggregate

Aggregate household consumption

Aggregate government consumption

Unemployment

Output price

Price of Armington aggregate

Price of electricity $\left(=P A_{E L E}\right)$

Price of material aggregate

Price of fossil fuel aggregate

Composite price for investment

ROW export and import price 
Table A1: continued

\begin{tabular}{|c|c|}
\hline$P C$ & Composite price for aggregate household demand (utility price index) \\
\hline$P Z$ & Composite price for government demand \\
\hline$P K$ & Price of capital services \\
\hline$P L$ & (Rigid) wage rate \\
\hline PCO & Price of carbon emission rights (carbon tax) \\
\hline \multicolumn{2}{|l|}{ Income variables } \\
\hline$M_{R A}$ & Income of representative agent \\
\hline \multicolumn{2}{|l|}{ Auxiliary variables } \\
\hline \multicolumn{2}{|l|}{ Endowments } \\
\hline $\bar{K}$ & Aggregate capital endowment \\
\hline $\bar{L}$ & Aggregate labor endowment \\
\hline$\overline{C O}$ & Endowment with carbon emission rights \\
\hline \multicolumn{2}{|c|}{ Input and output coefficients (per unit demand and supply) } \\
\hline $\mathrm{a}_{i}^{K}$ & Capital demand \\
\hline $\mathrm{a}_{i}^{L}$ & Labor demand \\
\hline $\mathrm{a}_{j i}^{Y}$ & Intermediate demand for Armington good \\
\hline $\mathrm{a}_{j}^{C}$ & Private demand for Armington good \\
\hline $\mathrm{a}_{j}^{\mathrm{Z}}$ & Government demand for Armington good \\
\hline $\mathrm{a}_{j}^{I}$ & Investment demand for Armington good \\
\hline $\mathrm{a}_{i}^{H}$ & Demand for domestic production \\
\hline $\mathrm{a}_{i}^{M}$ & Demand for imports \\
\hline $\mathrm{a}_{i}^{D}$ & Supply to domestic market \\
\hline $\mathrm{a}_{i}^{X}$ & Supply to export market \\
\hline $\mathrm{a}_{i}^{C O}$ & Carbon coefficient \\
\hline \multicolumn{2}{|l|}{ Other parameters } \\
\hline $\bar{Z}$ & Exogenously-specified (fixed) demand for public output \\
\hline $\bar{I}$ & (Fixed) aggregate investment level \\
\hline$D$ & Balance of payment surplus \\
\hline$T R$ & Lump sum transfers \\
\hline$t$ & Income tax \\
\hline$\alpha_{K L}, \alpha_{E L}, \alpha_{M L}, \alpha_{F L}$ & Cost price coefficients \\
\hline$\gamma_{K_{i}}, \gamma_{L_{i}}, \gamma_{E_{i}}, \gamma_{M_{i}}, \gamma_{F_{i}}$ & Calibrated cost price parameters \\
\hline $\mathrm{b}, \mathrm{c}, \mathrm{d}, \mathrm{e}, \mathrm{f}, \mathrm{g}, \mathrm{h}$ & Technology coefficients \\
\hline
\end{tabular}


Table 2A: Key substitution elasticities

\begin{tabular}{llc}
\hline \multicolumn{2}{l}{ Description } & Value \\
\hline \multicolumn{2}{l}{ Substitution elasticities in production } \\
$\sigma_{M} \quad$ Material vs. material & 0.5 \\
$\sigma_{F}$ & Fossil fuel vs. fossil fuel & 0.3 \\
Substitution elasticities in private demand & \\
$\sigma_{C} \quad$ Energy goods vs. non-energy goods & 0.8 \\
& Non-energy good vs. non-energy good & 1 \\
Substitution elasticities in government demand & 1 \\
$\sigma_{G}$ & Fossil fuel vs. fossil fuel & 0.8 \\
& Fossil fuels vs. non-fossil fuels & 1 \\
Elasticities in international trade (Armington) & 1 \\
$\sigma_{A}$ & Substitution elasticity between imports vs. domestic inputs & 4.0 \\
$\varepsilon$ & Transformation elasticity domestic vs. export & 4.0 \\
\hline
\end{tabular}

